\section{Peach Tree Vegetative and Root Growth Respond to Orchard Floor Management}

\author{
Michael L. Parker ${ }^{1}$ \\ Department of Horticultural Science, North Carolina State University, Box \\ 7609, Raleigh, NC 27695-7609
}

John R. Meyer ${ }^{2}$

Department of Entomology, North Carolina State University, Box 7626, Raleigh, NC 27695-7626

Additional index words. Prunus persica, tree growth, root density, root distribution

\begin{abstract}
Peach (Prunus persica L. Batsch. 'Biscoe'/Lovell) trees were grown in a sandy loam soil under six orchard floor management systems, including five vegetative covers (continuous under the tree) and a vegetation-free control (bare ground). At the end of the fifth year, trees grown in bare ground and nimblewill grass (Muhlenbergia schreberi J.F. Gmel.) had a significantly larger trunk cross-sectional area (TCSA) than trees grown in weedy plots, centipedegrass [Eremochloa ophiuroides (Munro) Hack.], or bahiagrass (Paspalum notatum Flugge). Trees grown in brome (Bromus mollis L.) did not differ significantly in TCSA from any other treatment. Soil profile excavations of the root system revealed that trees grown in bare ground or with nimblewill had significantly higher root densities than those in the weedy plots or grown with bahiagrass. Vector analysis of root distribution indicated that trees grown in bare ground or nimblewill rooted deeper than trees in all other treatments. The greatest reduction in deep rooting occurred with bahiagrass.
\end{abstract}

Renewed interest in using vegetative ground covers in peach orchards has sparked much controversy over the past decade. Proponents of vegetative covers cite benefits to soil structure and potential reductions in herbicide and pesticide use. Shribbs and Skroch (1986a, 1986b) grew 12 vegetative covers continuously under apple trees in an effort to identify ground cover species that could be grown in commercial orchards without decreasing yield, tree growth, or soil nutrient capacity. They concluded that nimblewill, a grass native to much of the eastern United States, was the least competitive ground cover. In addition, Meyer et al. (1992) reported that nimblewill did not promote arthropod pests (spider mites and catfacing insects-Hemiptera) and could be grown inside the dripline of the trees without inhibiting the growth of young trees.

In contrast, opponents of vegetative covers cite excessive competition for water and nutrients. Weller et al. (1985) reported that peach

Received for publication 5 July 1995. Accepted for publication 22 Dec. 1995. This research was funded partially by the North Carolina Agricultural Research Service and the North Carolina Cooperative Extension Service. We appreciate the technical assistance of Thurman Weaver, Bernadette Clark, and Ann Green. The cost of publishing this paper was defrayed in part by the payment of page charges. Under postal regulations, this paper therefore must be hereby marked advertisement solely to indicate this fact.

${ }^{1}$ Assistant Professor.

${ }^{2}$ Professor. trees grown in varying densities of bermudagrass had reduced tree growth and resulted in a potential 2- to 3-year delay in fruit production. Allelopathy was reported as a potential inhibitor of tree growth. Layne and Tan (1988) recommended that peach orchard floor management consist of permanent row middles of creeping red fescue (Festuca rubra L.) with a vegetation-free tree row with trickle irrigation. In another study, growth of 4-year-old, field-grown peach trees in tall fescue $(F$. arundinacea Schreb.) increased as the area of the vegetation-free zone around the tree increased (Welker and Glenn, 1989). The size of the vegetation-free zone is critical, as indicated in a greenhouse study by Glenn and Welker (1991), where tall fescue and Poa trivialis L. sod reduced growth of young peach trees when grown over $50 \%$ of the tree's root system.

In addition to vegetative tree growth, root growth also is affected by the orchard floor management system. In peach orchards maintained by mechanical tillage, root length and weight were reduced (Cockroft and Wallbrink, 1966). Atkinson and White (1976) reported that most root growth in apple (Malus domestica Borkh.) occurred in a vegetationfree strip under the trees. Parker et al. (1993) evaluated the effect of six orchard floor management systems on peach and reported a differential treatment effect on root density and distribution. Trees grown in tall fescue had lower root densities than trees maintained vegetation-free or with less competitive grasses, such as Kentucky bluegrass (Poa pratensis $\mathrm{L}$.). However, a 1.2-m, vegetation- free strip in the tree row was maintained in all of the vegetative treatments. Glenn and Welker (1989) reported that peach trees grown in the greenhouse in tall fescue sod had fewer roots $<1 \mathrm{~mm}$ in diameter, but there was no effect on roots $>1 \mathrm{~mm}$.

Our objective was to evaluate vegetative tree growth, root density, and root distribution of peach trees grown in six orchard floor management systems. The five vegetative covers in this study were grown completely under the trees.

\section{Materials and Methods}

In Mar. 1988, six orchard floor management systems were established at the Sandhills Research Station, Jackson Springs, N.C. The soil types were a Candor sand and Eunola sandy loam. In Fall 1987, before planting, the soil for each tree was fumigated with $0.48 \mathrm{~kg}$ of methyl bromide ( $98 \%$ ) placed under a plastic sheet and released. The six systems were established in three blocked replications (18 plots) in a randomized complete-block design to account for any differences in soil type or environmental conditions. Each plot measured $9.1 \times 10.7 \mathrm{~m}$ and was separated from adjacent plots by a $2-\mathrm{m}$, vegetation-free strip. The vegetative covers in this study were selected to represent a wide range of vegetative competition with peach tree growth, and all had been identified as nonhosts for ring nematode [Criconemella xenoplax (Raski) Luc and Raski] (Zehr et al., 1986, 1990), a predisposing factor to peach tree short life. The six treatments were bare ground, maintained with herbicide; weedy, no vegetation control; nimblewill; brome; centipedegrass; and bahiagrass (Meyer et al., 1992). The herbicides used to maintain the bare ground treatment were 6-chloro- $N, N^{\prime}$-diethyl-1,3,5-triazine-2,4diamine (simazine) (2.5 kg a.i./ha) and 1,1'dimethyl-4,4'-bipyridinium ion (paraquat) (1.1 $\mathrm{kg}$ a.i./ha) applied annually in early spring, with a second application of paraquat in midsummer to control annual weeds.

In Apr. 1988, four June-budded peach ('Biscoe'/Lovell) trees were planted in each plot. Trees were spaced $3 \mathrm{~m}$ apart within and between rows and $3 \mathrm{~m}$ from the edge of the plot. Treatment effects on survival and growth of trees and pest populations were reported by Meyer et al. (1992) after the third growing season. No yield data are reported due to crop loss resulting from spring frost and freeze conditions.

In Dec. 1992, two representative trees in each block (six trees per treatment) were selected to determine the treatment effects on peach tree growth, root density, and distribution. Trunk diameter of each tree was measured, and trunk cross-sectional area (TCSA) was calculated $\left(\pi r^{2}\right)$. Trees then were cut off $70 \mathrm{~cm}$ above the soil surface to facilitate equipment movement. A backhoe was used to excavate trenches $60 \mathrm{~cm}$ from the tree on the east and west side of two trees in each replication. Trench faces were prepared as described by Layne et al. (1986) to a depth of $\approx 1.5 \mathrm{~m}$. Root distribution and density were recorded using 
the profile wall method as described by Bohm (1979).

A $1.0 \times 1.0-\mathrm{m}$ aluminum grid frame divided into 100 identical sections $(10 \times 10 \mathrm{~cm})$ was used to map root distribution. Grid frames were placed on the profile wall beginning at the trunk and extending 1 morth and south on the east and west sides of each tree. This resulted in four grid maps per tree. Root locations were plotted on data sheets that duplicated Cartesian axes of the grid frames. Roots were recorded as one of three size categories according to diameter: small $(<2 \mathrm{~mm})$, medium ( 2 to $5 \mathrm{~mm})$, and large ( $>5 \mathrm{~mm})$. Peach roots were easily distinguishable by color and texture from the roots of the vegetative covers used in this study.

A form of vector analysis that assigned a depth (vertical) and a horizontal (lateral) value to each root, based on its position in the grid frame, was used to determine the effect of each treatment on root distribution. For example, roots with a vector value of $(3,4)$ would be located three grid sectors below the soil surface and four grid sectors away from the tree. For vector analysis, a depth (D) and horizontal component $(\mathrm{H})$ were calculated by totaling root counts in vertical columns (depth) (10) and horizontal rows of the profile grids (10) and multiplying the totals by their positional component (from 1 to 10). A single vector sum (M) was calculated for all roots within each grid frame by incorporating $\mathrm{H}$ and $\mathrm{D}$ into the Pythagorean theorem: $\mathrm{M}=\left[(\mathrm{H})^{2}+(\mathrm{D})^{2}\right]^{1 / 2}$.

To evaluate relative root distribution tendencies (mean vector components), independent of total root counts for each treatment, $\mathrm{H}$ and $\mathrm{D}$ for each treatment were divided by the total root count for that treatment (i.e., mean $\mathrm{D}$ $=\mathrm{D} \div$ total root count; mean $\mathrm{H}=\mathrm{H} \div$ total root count). Finally, the slope of the vector sum was calculated by dividing the $\mathrm{D}$ by its $\mathrm{H}(\mathrm{D} \div$ $H)$. This unitless value allows direct comparison of the ratio between depth and lateral spread for each tree's root system.

Data for TCSA were evaluated as a randomized complete block (RCB) in an analysis of variance (ANOVA), with two trees as replications within each of the three blocks. Statistical analysis for the root distribution data showed no significant differences among the four grid faces of each tree. Therefore, all data from each grid frame per tree were pooled. Block effects were not significant in the ANOVA for root density and distribution, so total root count, root count within each size

Table 1. Trunk cross-sectional area (TCSA) for 5year-old peach trees grown in six orchard floor management systems.

\begin{tabular}{lc}
\hline \hline Treatment & TCSA $\left(\mathrm{cm}^{2}\right)$ \\
\hline Bare ground & $73.3 \mathrm{a}^{\mathrm{z}}$ \\
Nimblewill & $71.9 \mathrm{a}$ \\
Brome & $40.9 \mathrm{ab}$ \\
Weedy & $31.8 \mathrm{~b}$ \\
Centipedegrass & $31.0 \mathrm{~b}$ \\
Bahiagrass & $6.6 \mathrm{~b}$ \\
$\mathrm{CV}=29.8$ & \\
\hline
\end{tabular}

${ }^{2}$ Mean separation within columns by Duncan's multiple range test at $P \leq 0.05$. Data shown are the mean of six trees. category, vector components (D and $\mathrm{H})$, mean vector components, $M$, and slope $(D \div H)$ were evaluated in a completely random design (CRD). The SAS general linear model and ANOVA procedures (SAS Institute, Cary, N.C.) were used for RCB and CRD analyses. Significant differences between treatment means were detected with Duncan's multiple range test at $P \leq 0.05$.

\section{Results and Discussion}

Tree growth. After five growing seasons, tree growth, as measured by TCSA, was best with bare ground or nimblewill. These trees were significantly larger than those in all other treatments, except brome (Table 1). Meyer et al. (1992) reported similar results on the trees in this experiment after the third growing season, except that trees grown in centipedegrass were larger than trees in weedy or bahiagrass plots. Glenn and Welker (1989, 1991) also reported reduced growth of peach when grown in tall fescue or Poa trivialis sod compared to those grown vegetation-free. Nimblewill also was one of the least competitive vegetative covers with apple (Shribbs and Skroch, 1986a).

Root density. Root density, as measured by root counts in three size categories and total root counts, also was affected significantly by orchard floor management (Table 2). Most of the roots excavated in this study were $<2 \mathrm{~mm}$ in diameter, consistent with the results of Layne et al. (1986) who described root density on 11-year-old 'Harken' peach trees. Trees grown in weedy or bahiagrass plots had significantly fewer small roots than trees in bare ground or nimblewill. This same trend also occurred for total root count, which was expected because small roots accounted for $89 \%$ to $96 \%$ of the total in this study. Trees grown in weedy, centipedegrass, or bahiagrass plots had significantly fewer medium and large roots than trees grown in bare ground or nimblewill. Root counts for trees grown in brome were intermediate. In this study, medium roots and large roots accounted for $3 \%$ to $7 \%$ and $1 \%$ to $4 \%$, respectively, of all roots. Weedy or bahiagrass plots contained the fewest roots in all size categories measured. The differences in root counts in all three size categories differed from the results of Parker et al. (1993) and Glenn and Welker (1989), who saw no differences in the number of large roots as a result of different vegetative covers but did report treatment differences in the number of small roots. However, trees in this study were examined after the fifth growing season, whereas those in the previously mentioned studies were examined after the third and first growing season, respectively.

Root distribution. Percentage of roots in the surface $10 \mathrm{~cm}$ of soil for each treatment accounted for $\approx 20 \%$ of the root system for bare ground or nimblewill plots compared to $>32 \%$ for the weedy or bahiagrass plots. At the deepest zone evaluated $(90$ to $100 \mathrm{~cm}$ beneath the soil surface), trees in bare ground or nimblewill (3.9\% and $4.2 \%$, respectively) had three to four times more roots than trees grown in weedy or bahiagrass plots $(1.1 \%$ and $1.4 \%$, respectively).

To further investigate root distribution, vector analysis provides a convenient way to evaluate not only the size of a tree's root system, but also its horizontal $(\mathrm{H})$ and vertical distribution (D) within the soil. The vector

Table 2. Total number of peach roots and distribution into small-, medium-, and large-diameter categories for 5-year-old trees grown in six orchard floor management systems.

\begin{tabular}{lcccc}
\hline & \multicolumn{4}{c}{ Roots $/ \mathrm{m}^{2}$} \\
\cline { 2 - 5 } Treatment & Small $(<2 \mathrm{~mm})$ & Medium $(2-5 \mathrm{~mm})$ & Large $(>5 \mathrm{~mm})$ & Total \\
\cline { 2 - 5 } Bare ground & $165 \mathrm{a}^{\mathrm{z}}$ & $13 \mathrm{a}$ & $8 \mathrm{a}$ & $186 \mathrm{a}$ \\
Nimblewill & $162 \mathrm{a}$ & $11 \mathrm{ab}$ & $8 \mathrm{a}$ & $181 \mathrm{a}$ \\
Brome & $110 \mathrm{ab}$ & $9 \mathrm{bc}$ & $5 \mathrm{ab}$ & $124 \mathrm{ab}$ \\
Weedy & $67 \mathrm{~b}$ & $5 \mathrm{~d}$ & $2 \mathrm{bc}$ & $74 \mathrm{~b}$ \\
Centipedegrass & $121 \mathrm{ab}$ & $6 \mathrm{~cd}$ & $2 \mathrm{bc}$ & $129 \mathrm{ab}$ \\
Bahiagrass & $67 \mathrm{~b}$ & $2 \mathrm{e}$ & $1 \mathrm{c}$ & $70 \mathrm{~b}$ \\
\hline
\end{tabular}

${ }^{2}$ Mean separation within columns by Duncan's multiple range test at $P \leq 0.05$. Data shown are the mean of 12 observations.

Table 3. Vector analysis components for peach tree root distribution under six orchard floor management systems.

\begin{tabular}{|c|c|c|c|c|c|c|}
\hline \multirow[b]{3}{*}{ Treatment } & \multicolumn{4}{|c|}{ Component } & \multirow[b]{3}{*}{$\mathbf{M}^{\mathrm{w}}$} & \multirow{3}{*}{$\begin{array}{l}\mathrm{D} / \mathrm{H}^{\mathrm{z}} \\
\text { slope }\end{array}$} \\
\hline & \multicolumn{2}{|c|}{ Depth } & \multicolumn{2}{|c|}{ Horizontal } & & \\
\hline & $\mathrm{D}^{\mathrm{z}}$ & Mean $^{y}$ & $\mathrm{H}^{\mathrm{z}}$ & $\operatorname{Mean}^{x}$ & & \\
\hline Bare ground & $709 \mathrm{a}^{\mathrm{v}}$ & $0.95 \mathrm{ab}$ & $967 \mathrm{a}$ & $1.30 \mathrm{a}$ & $1201 \mathrm{a}$ & $0.73 \mathrm{ab}$ \\
\hline Nimblewill & $785 \mathrm{a}$ & $1.07 \mathrm{a}$ & $950 \mathrm{a}$ & $1.30 \mathrm{a}$ & $1233 \mathrm{a}$ & $0.82 \mathrm{a}$ \\
\hline Brome & $412 b$ & $0.82 \mathrm{a}-\mathrm{c}$ & $654 \mathrm{ab}$ & $1.32 \mathrm{a}$ & $775 \mathrm{ab}$ & $0.63 \mathrm{~b}$ \\
\hline Weedy & $223 \mathrm{~b}$ & $0.73 \mathrm{c}$ & $349 \mathrm{~b}$ & $1.19 \mathrm{a}$ & $414 b$ & $0.62 \mathrm{~b}$ \\
\hline Centipedegrass & $428 \mathrm{~b}$ & $1.01 \mathrm{a}$ & $643 \mathrm{ab}$ & $1.39 \mathrm{a}$ & $776 \mathrm{ab}$ & $0.74 \mathrm{ab}$ \\
\hline Bahiagrass & $185 \mathrm{~b}$ & $0.61 \mathrm{c}$ & $367 \mathrm{~b}$ & $1.29 \mathrm{a}$ & $412 \mathrm{~b}$ & $0.47 \mathrm{c}$ \\
\hline
\end{tabular}

${ }^{2} \mathrm{D}=$ depth component; $\mathrm{H}=$ horizontal component.

${ }^{\mathrm{y}}$ Mean depth component $=$ depth component/total root count.

${ }^{\mathrm{x}}$ Mean horizontal component $=$ horizontal component/total root count.

"Vector magnitude.

'Mean separation within columns by Duncan's multiple range test at $P \leq 0.05$. Data shown are the mean of 12 observations. 
sum (M) of all roots is a function of the total number of roots (root density) as well as their distance from the base of the tree (H and D). In contrast, the slope $(\mathrm{D} \div \mathrm{H})$ of $\mathrm{M}$ is a ratio between $\mathrm{H}$ and $\mathrm{D}$ of all root vectors, making it independent of tree size or root density. The slope approaches 1.0 when the roots are randomly distributed in the zone under investigation. Values $>1.0$ are associated with root distributions that are concentrated deeper in the soil being sampled; values $<1.0$ are encountered when roots are clustered near the soil surface.

$\mathrm{D}$ was largest for trees in bare ground and nimblewill, indicating that these treatments allowed deepest root growth (Table 3). H (lateral) for bare ground and nimblewill also was larger than for weedy or bahiagrass, indicating that these treatments had more horizontal rooting farther from the tree. The resultant $\mathrm{M}$ indicated that trees in weedy or bahiagrass plots had a smaller root system, with limited root distribution in depth and lateral spread, than bare ground or nimblewill plots. This result was consistent with the treatment effect on root count (Table 2).

Because there were large and significant differences in root densities between the orchard floor management treatments, those with the most rooting would be expected to have more roots throughout the measured profile. However, when the mean depth component was examined to compensate for root count differences, the bahiagrass or weedy plots had less deep root growth than all other treatments except brome (Table 3). Additionally, the mean $\mathrm{H}$ showed no difference in relative lateral root distribution among all treatments.

The slope calculated for each $\mathrm{M}$ indicated the degree to which that root distribution was restricted. The bahiagrass resulted in the lowest slope of all treatments, indicating that trees in this treatment had significantly more roots concentrated close to the surface than the other treatments. Considering the slope and the mean $\mathrm{D}$ and $\mathrm{H}$, the bahiagrass resulted in peach trees with the shallowest root system. Although root counts would be expected to decrease with depth and distance from the tree (Bechenbach and Gourley, 1932; Parker et al., 1993), Parker et al. (1993) reported this reduction with depth to be uniform in 3-year-old peach trees grown in four vegetative covers. With the use of vector analysis, we found a differential reduction in tree rooting depth under the vegetative covers examined. Root distribution also can be represented visually with a shading diagram (Fig. 1) developed using root densities in each quadrant of the grid frame. The data have been combined from all locations in each treatment to represent a 1-m square profile wall with the tree being represented by the arrow in the upper left corner of each grid.

Based on tree growth, root density, and root distribution, the six ground cover treatments appear to represent three distinct levels of vegetative competition. Bare ground or nimblewill treatments posed little competition to tree growth, while the weedy plot or bahiagrass were most competitive; brome and centipede were intermediate.
Bahiagrass has a vigorous and aggressive root system that may help explain its high degree of competition with peach tree growth. Evert et al. (1992) reported that peach trees grown in bahiagrass had greatly reduced TCSA compared to trees grown in a bare ground treatment. They further suggested that bahiagrass may be considered as a preplant treatment to reduce nematode populations but never in a newly planted orchard. Bahiagrass is a relatively deep-rooted plant with an average root depth of $60 \mathrm{~cm}$ and a maximum rooting depth of $245 \mathrm{~cm}$ (Burton et al., 1954). Burton et al. (1954) also reported bahiagrass to be one of the most prolific root producers of southern grasses, with $46 \%$ more roots than six other grasses in their study. Because of its aggressive and deep rooting characteristics, bahiagrass is used in western states to penetrate dense soil layers and increase the productivity of the soil for subsequent crops (Elkins, 1985; Elkins et al., 1977).

Our research illustrates that the selection of an orchard floor cover is crucial for maximizing peach tree growth and, therefore, orchard productivity and profitability. A traditional orchard management system composed of a vegetative orchard alley with a vegetation-free strip in the tree row is not necessarily better than a noncompetitive vegetative cover on the entire orchard floor. The potential advantages of a total vegetative cover may include reduced mechanical tillage, mowing, and herbicide usage; improved soil structure (Haynes, 1980); decreased erosion; and reduced freeze injury to the tree (Layne et al.,
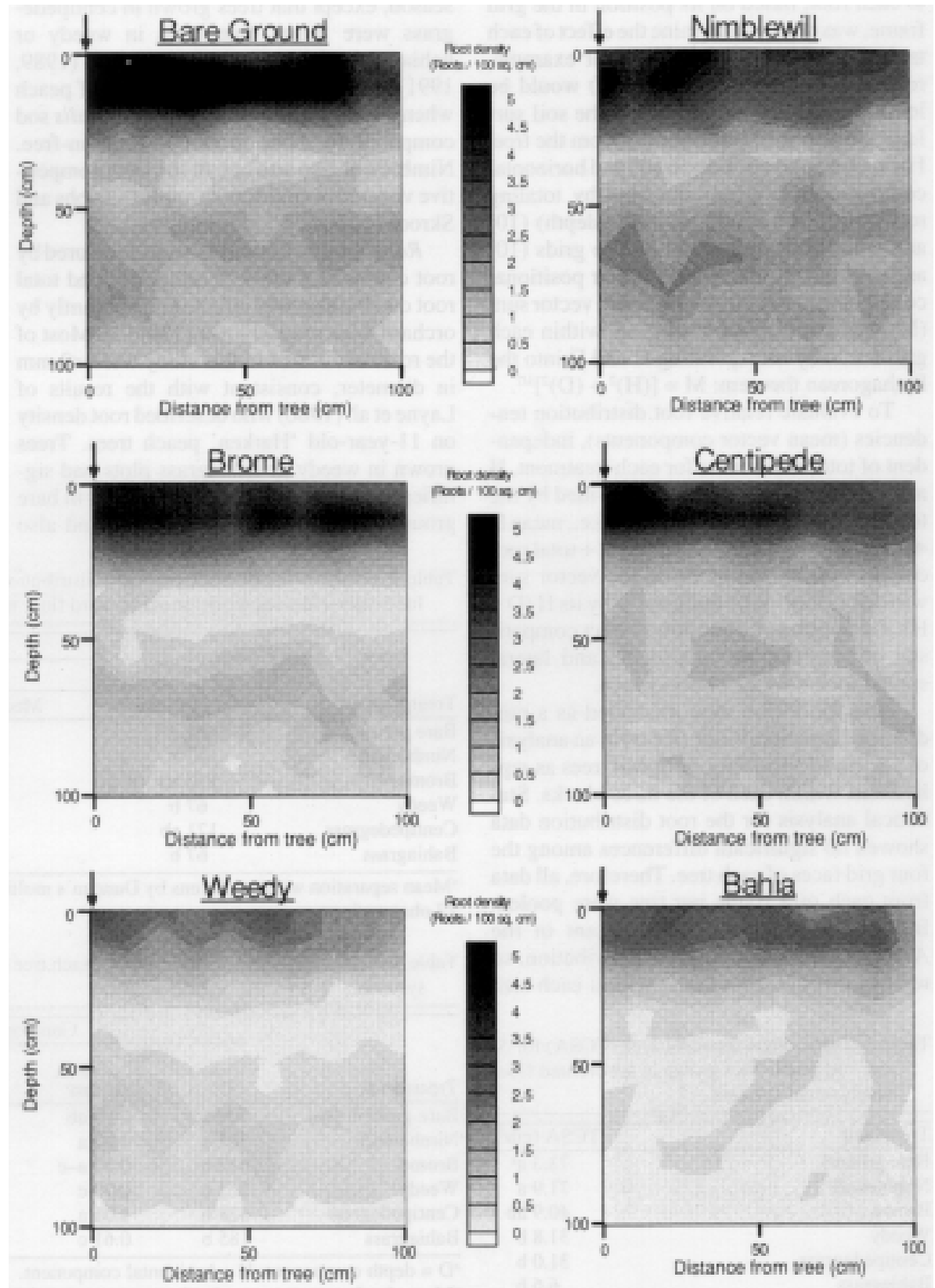

Fig. 1. Graphic representation of peach rooting densities for peach trees grown in six orchard floor management systems. Tree trunk location is indicated by arrow in upper left corner of each diagram. Figure represents rooting density parallel to the tree row $60 \mathrm{~cm}$ outward from the trunk of the tree and $1 \mathrm{~m}$ deep and $1 \mathrm{~m}$ laterally in the tree row. 
1986), all of which contribute to increased orchard profitability.

However, identification, selection, and required management of noncompetitive vegetative covers must be undertaken. Nimblewill has been identified by others as posing little competition with fruit tree growth (Meyer et al., 1992; Shribbs and Skroch, 1986a). This conclusion also was supported in this study, but nimblewill requires special management. The study by Shribbs and Skroch (1986a, 1986b) was conducted in a clay loam soil in an area where nimblewill is a native vegetative cover. However, the work by Meyer et al. (1992), as well as our study, were conducted in lighter, sandy soil, where nimblewill has proven harder to establish and maintain. But once established, as indicated in our study, nimblewill provides a noncompetitive orchard floor cover. Therefore, further work is needed to improve management techniques for establishing nimblewill or to identify other vegetative covers that are similarly noncompetitive.

\section{Literature Cited}

Atkinson, D. and G.C. White. 1976. The effect of the herbicide strip system of management on root growth of young apple trees and the soil zones from which they take up mineral nutrients. 1975 Rpt. East Malling Res. Sta., Kent, England. p. 165-167.

Bechenbach, J. and J.H. Gourley. 1932. Some effects of different cultural methods upon root distribution of apple trees. Proc. Amer. Soc. Hort. Sci. 29:202-204.
Bohm, W. 1979. Methods of studying root systems. Ecological Studies 33. Springer-Verlag, Berlin.

Burton, G.W., E.H. DeVane, and R.L. Carter. 1954. Root penetration, distribution and activity in southern grasses measured by yields, drought symptoms and $\mathrm{P}^{32}$ uptake. Agron. J. 46:229233.

Cockroft, B. and J.C. Wallbrink. 1966. Root distribution of orchard trees. Austral. J. Agr. Res. 17:49-54.

Elkins, C.B. 1985. Plant roots as tillage tools, p. 519-523. In: Traction and transport as related to cropping systems. Proc. Intl. Conf. on Soil Dynamics. vol. 3. Auburn Univ., Auburn, Ala. 17 19 Apr. 1985.

Elkins, C.B., R.L. Haaland, and C.S. Hoveland. 1977. Grass roots as a tool for penetrating soil hardpans and increasing crop yields, p. 21-26. In: Proc. 34th Southern Pasture and Forage Crop Improvement Conf. Auburn Univ., Auburn, Ala., 12-14 Apr. 1977.

Evert, D.R., P.F. Bertrand, and B.G. Mullinix, Jr. 1992. Nematode populations and peach tree survival, growth, and nutrition at an old orchard site. J. Amer. Soc. Hort. Sci. 117:6-13.

Glenn, D.M. and W.V. Welker. 1989. Peach root development and tree hydraulic resistance under tall fescue sod. HortScience 24:117-119.

Glenn, D.M. and W.V. Welker. 1991. Soil management affects shoot and root growth, nutrient availability, and water uptake of young peach trees. J. Amer. Soc. Hort. Sci. 116:238-241.

Haynes, R.J. 1980. Effects of soil management practices on soil physical properties, earthworm population and tree root distribution in a commercial apple orchard. Soil Tillage Res. 1:269280.

Layne, E.C. and C.S. Tan. 1988. Influence of culti- vars, ground covers, and trickle irrigation on early growth, yield, and cold hardiness of peaches on fox sand. J. Amer. Soc. Hort. Sci. 113:518 525.

Layne, R.E.C., C.S. Tan, and R.L. Perry. 1986. Characterization of peach roots in fox sand as influenced by sprinkler irrigation and tree density. J. Amer. Soc. Hort. Sci. 111:670-677.

Meyer, J.R., E.I. Zehr, R.L. Meagher, Jr., and S.K Salvo. 1992. Survival and growth of peach trees and pest populations in orchard plots managed with experimental ground covers. Agr., Ecosystems and Environ. 41:353-363.

Parker, M.L., J. Hull, and R.L. Perry. 1993. Orchard floor management affects peach rooting. J. Amer. Soc. Hort. Sci. 118:714-718.

Shribbs, J.M. and W.A. Skroch. 1986a. Influence of 12 ground cover systems in young 'Smoothee Golden Delicious' apple trees: I. Growth. J. Amer. Soc. Hort. Sci. 111:525-528.

Shribbs, J.M. and W.A. Skroch. 1986b. Influence of 12 ground cover systems in young 'Smoothee Golden Delicious' apple trees: II. Nutrition. J. Amer. Soc. Hort. Sci. 111:529-533.

Welker, W.V. and D.M. Glenn. 1989. Sod proximity influences the growth and yield of young peach trees. J. Amer. Soc. Hort. Sci. 114:856859.

Weller, S.C., W.A. Skroch, and T.J. Monaco. 1985 Common bermudagrass (Cynodon dactylon) interference in newly planted peach (Prunus persica) trees. Weed Sci. 33:50-56.

Zehr, E.I., J.B. Aiken, J.M. Scott, and J.R. Meyer. 1990. Additional hosts for the ring nematode, Criconemella xenoplax. J. Nematol. 22:86-89.

Zehr, E.I., S.A. Lewis, and M.J. Bonner. 1986. Some herbaceous hosts of the ring nematode (Criconemellaxenoplax).PlantDis.70:1066-1069. 